\title{
Materials Characterization of Feraheme/Ferumoxytol and Preliminary Evaluation of Its Potential for Magnetic Fluid Hyperthermia
}

\author{
John P. Bullivant ${ }^{1}$, Shan Zhao ${ }^{1}$, Brad J. Willenberg ${ }^{1}$, Bettina Kozissnik ${ }^{2,3}$, \\ Christopher D. Batich ${ }^{1,3}$ and Jon Dobson ${ }^{1,2,3, *}$
}

1 Department of Materials Science \& Engineering, University of Florida, Gainesville, FL 32611-6400, USA; E-Mails: jpbulli@ufl.edu (J.P.B.); shanzhao401@gmail.com (S.Z.); yoda@ufl.edu (B.J.W.); cbati@mse.ufl.edu (C.D.B.)

2 J. Crayton Pruitt Family Department of Biomedical Engineering, University of Florida, Gainesville, FL 32611-6131, USA; E-Mail: b.kozissnik@ufl.edu

3 Institute for Cell Engineering and Regenerative Medicine, University of Florida, Gainesville, FL 32611-6131, USA

* Author to whom correspondence should be addressed; E-Mail: jdobson@ufl.edu; Tel.: +1-352-273-9222; Fax: +1-352-273-9221.

Received: 26 June 2013; in revised form: 5 August 2013 / Accepted: 21 August 2013 / Published: 26 August 2013

\begin{abstract}
Feraheme, is a recently FDA-cleared superparamagnetic iron oxide nanoparticle (SPION)-based MRI contrast agent that is also employed in the treatment of iron deficiency anemia. Feraheme nanoparticles have a hydrodynamic diameter of $30 \mathrm{~nm}$ and consist of iron oxide crystallites complexed with a low molecular weight, semi-synthetic carbohydrate. These features are attractive for other potential biomedical applications such as magnetic fluid hyperthermia (MFH), since the carboxylated polymer coating affords functionalization of the particle surface and the size allows for accumulation in highly vascularized tumors via the enhanced permeability and retention effect. This work presents morphological and magnetic characterization of Feraheme by transmission electron microscopy (TEM), Energy dispersive X-ray spectroscopy (EDX), and superconducting quantum interference device (SQUID) magnetometry. Additionally, the results of an initial evaluation of the suitability of Feraheme for MFH applications are described, and the data indicate the particles possess promising properties for this application.
\end{abstract}


Keywords: Feraheme; magnetic fluid hyperthermia; magnetic nanoparticles; MRI contrast

\section{Introduction}

Superparamagnetic iron oxide nanoparticle (SPION) contrast agents for MRI generally consist of a biocompatible polymer coating or matrix with superparamagnetic (ferri- or ferromagnetic) iron oxide cores [1-3]. Superparamagnetic particles are nanoscale particles in which quantum effects dominate over bulk effects. For iron oxides, this generally translates to diameters of less than $30 \mathrm{~nm}$. They exhibit strong magnetization in the presence of an applied field; however, upon removal of the field, they retain no permanent magnetization, making them ideal for in vivo applications where magnetic dipole-induced aggregation of particles within the vasculature would have the potential to cause embolization.

Inside the scanner, the SPIONs cause local perturbations of the magnetic field around the particles, resulting in detectable variations of the relaxation times of nearby proton spins after a probing RF pulse has been applied. Specifically, these local distortions increase proton dephasing, providing contrast enhancement in $\mathrm{T}_{2}$-weighted (spin-spin or transverse) MR images. In fact, the resulting $\mathrm{T}_{2}$-weighted images show signal intensity decreases, known as negative contrast, in regions where the SPIONs have aggregated [4].

Although many of these particles eventually end up naturally in the liver, the leaky vasculature present in solid tumors also promotes extravasation and accumulation — an effect known as "enhanced permeability and retention (EPR) - thereby providing contrast highlighting of the tumor against the surrounding tissue. The contrast effects are amplified when reactive cells associated with tumors also take up the particles (e.g., [5,6]). Implanted or injected cells that have been doped with SPIONs also can be tracked via $\mathrm{T}_{2}$-weighted $\mathrm{MR}$ imaging for applications in regenerative medicine and cell targeting (For review see [7]).

Though FDA-cleared, the main commercially available agents, such as Feridex/Comidex, have been withdrawn from the market [8]. Recently, a new SPION-based MRI contrast agent, Feraheme (also known as Ferumoxytol-AMAG Pharmaceuticals), has received a significant amount of attention due to its FDA-cleared status for use in humans, and there is keen interest to understand its magnetic properties. Feraheme is a SPION coated with a low molecular weight semi-synthetic carbohydrate. It is particularly indicated for the treatment of iron deficiency anemia in adult patients with chronic kidney disease [9]. Feraheme has a hydrodynamic diameter of $c a .30 \mathrm{~nm}$ and, most importantly for other potential biomedical applications, the carboxylated polymer coating allows for the bio-functionalization of the particle's surface [10].

To date, the molecular weight and iron release profile of feraheme have been investigated [11], as have some of the basic magnetic properties [10,12], and these studies have focused on bio-functionalization and MRI contrast. A thorough evaluation of the magnetic properties of Feraheme and consideration of its potential use in other biomedical applications, such as magnetic fluid hyperthermia (MFH), cell tracking/loading optimization, nanomagnetic cellular actuation, and nanomagnetic drug and gene delivery, have not yet been reported (For reviews of these applications see $[1,4,13]$ ). 
Magnetic fluid hyperthermia is a technique that utilizes the coupling of radiofrequency magnetic fields with magnetic nanoparticles to preferentially heat the particles compared to surrounding diamagnetic tissue. As the body is primarily diamagnetic, magnetic fields pass through relatively unimpeded, allowing the applied RF magnetic field to penetrate deep into tissue and deposit significant amounts of energy, primarily but not exclusively in the form of heat, to targets where MNPs have accumulated either via extravasation through leaky tumor vasculature or via biomolecular targeting of cell surface receptors. Herein, we present morphological and magnetic characterization data for Feraheme as well as the results of a preliminary evaluation of the suitability of this SPION for MFH applications.

\section{Results and Discussions}

\subsection{Transmission Electron Microscopy}

Selected area electron diffraction analysis is consistent with the lattice spacing of cubic maghemite $\left(\gamma-\mathrm{Fe}_{2} \mathrm{O}_{3}\right)$ cores (Figure 1a). The TEM morphological analysis shows that the electron-dense Feraheme cores are irregular in shape (Figure 1b) and have a mean diameter of approximately $3.25 \mathrm{~nm}$. Energy dispersive X-ray analysis confirms the presence of iron and oxygen in an approximately 30:70 atomic ratio (Figure 2a), where the copper and silicon peaks are associated with the Formvar microscope grids and the carbon from the polymer coating. As it is difficult to accurately measure oxygen via EDX due to its low atomic number, this ratio should be considered a rough estimate.

Figure 1. Transmission electron microscopy (TEM) of Feraheme (1:50 dilution with ultra-pure water). (a) Selected Area Diffraction image showing a cubic maghemite $\left(\gamma-\mathrm{Fe}_{2} \mathrm{O}_{3}\right)$ crystal structure; (b) Transmission Electron Micrograph showing electron-dense particle cores $<5 \mathrm{~nm}$ in diameter.

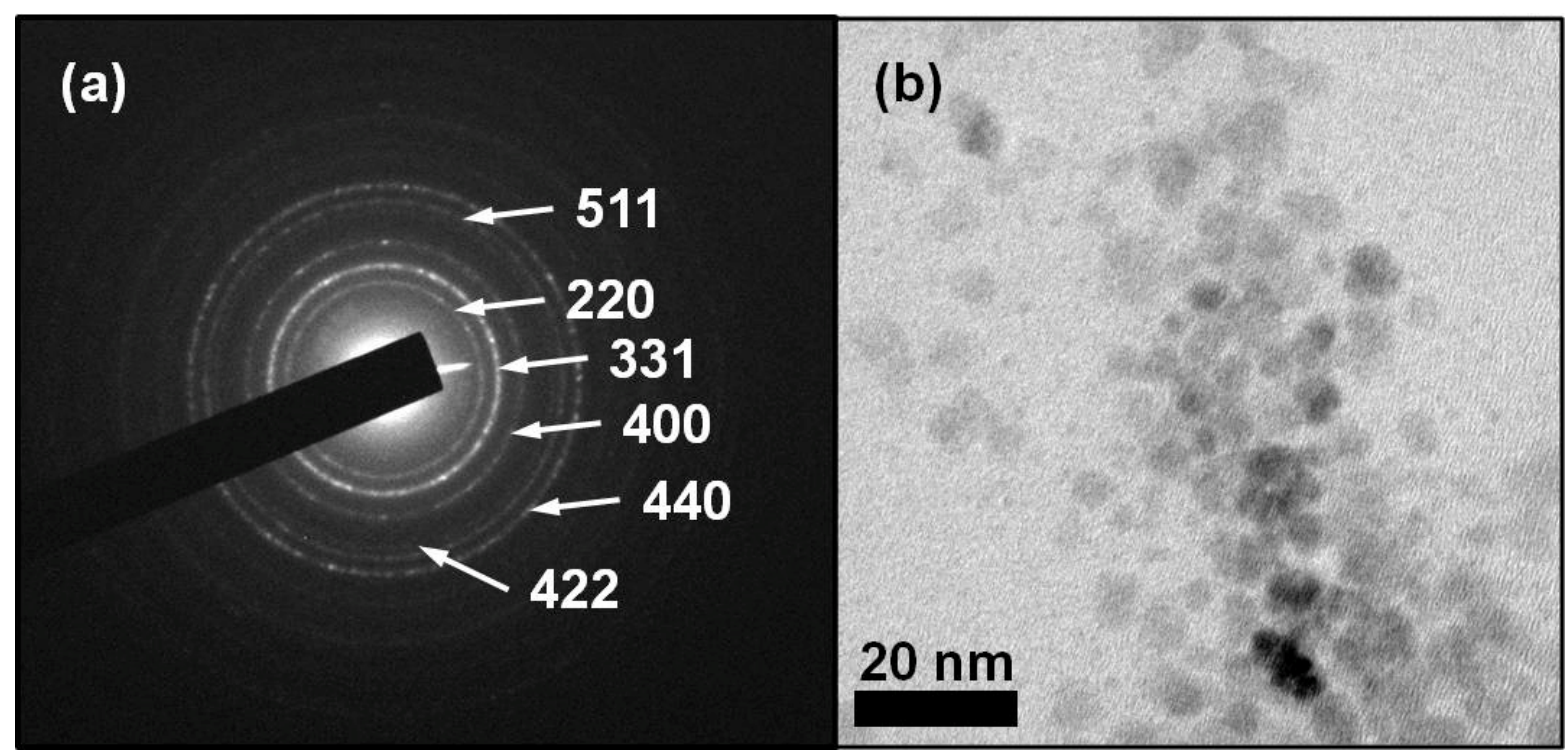




\subsection{Magnetic Measurements}

Hysteresis loops - a measure of the magnetization in a sample vs. applied magnetic field — at $300 \mathrm{~K}$ and $5 \mathrm{~K}$ show that Feraheme exhibits low coercivity (i.e., it is easily magnetized) superparamagnetic behavior at room temperature, consistent with sub-10 $\mathrm{nm}$ magnetite/maghemite crystallites as identified by TEM (Figures $1 \mathrm{~b}$ and $2 \mathrm{~b}$ ). At $5 \mathrm{~K}$, the open loop indicates that at least some of the iron oxide cores are blocked at this temperature, retaining a remanent magnetization even in the absence of an applied field (Figure 3b). The magnetization values observed at $300 \mathrm{~K}$ are slightly larger than those reported for ferumoxytol measured in fields up to $2 \mathrm{~T}$ [10] and for magnetite nanostructures studied up to $7 \mathrm{~T}[14]$.

Figure 2. (a) Energy Dispersive X-ray elemental analysis of the sample showing iron and oxygen peaks ( $\mathrm{Cu}$ and $\mathrm{Si}$ peaks are from the Formvar-coated copper grids); (b) Histogram of iron oxide crystallite particle sizes vs. fraction of total ( $y$-axis); measured using ImageJ.

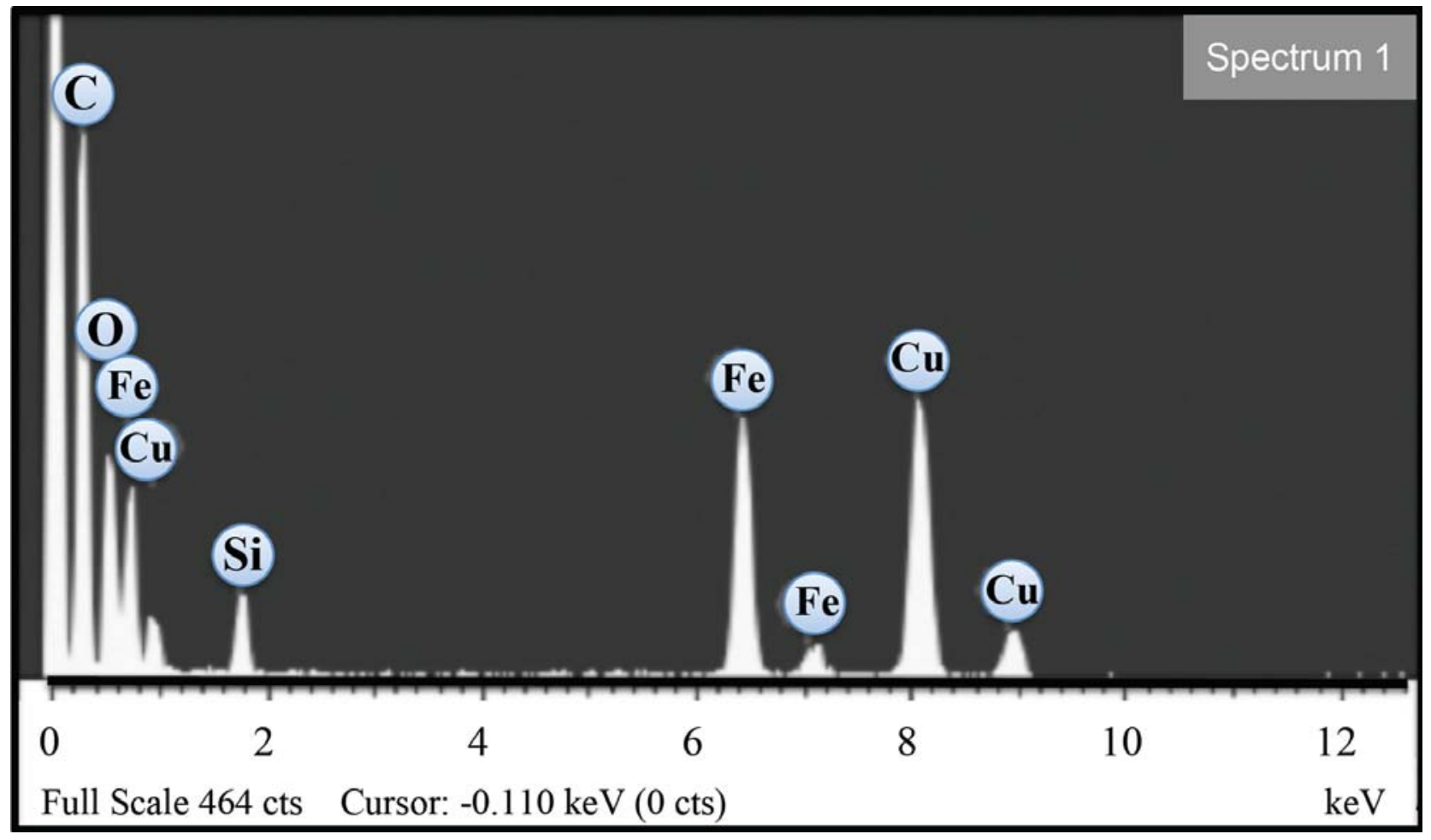

(a) 
Figure 2. Cont.

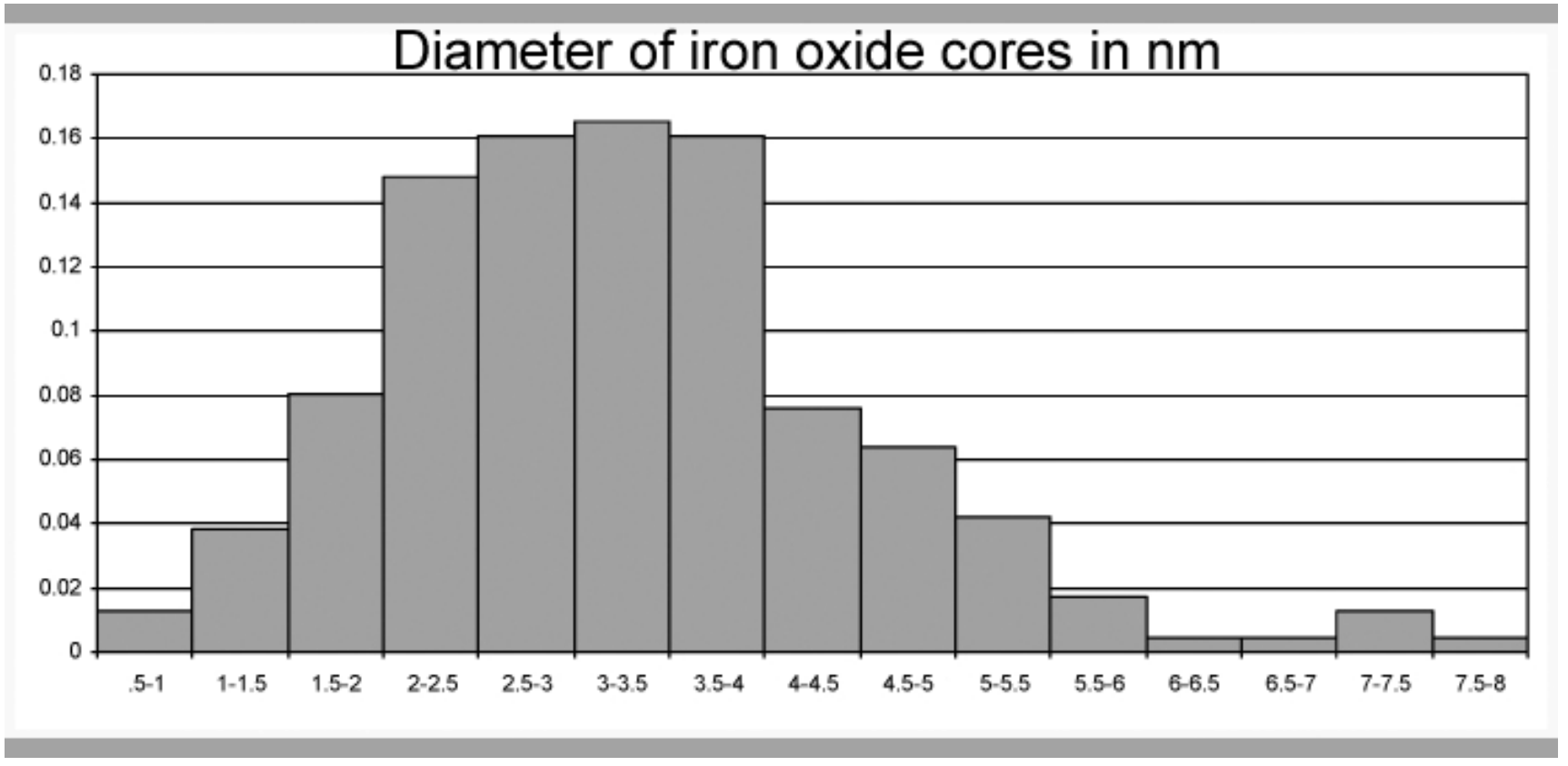

(b)

Figure 3. (a) Magnetization curves measured at $300 \mathrm{~K}$ (top) and $5 \mathrm{~K}$ (bottom). (b) Low magnetic field region of the hysteresis loop at $5 \mathrm{~K}$. The arrows indicate the directions of the magnetic field sweeps and the lines are guides for the eyes.
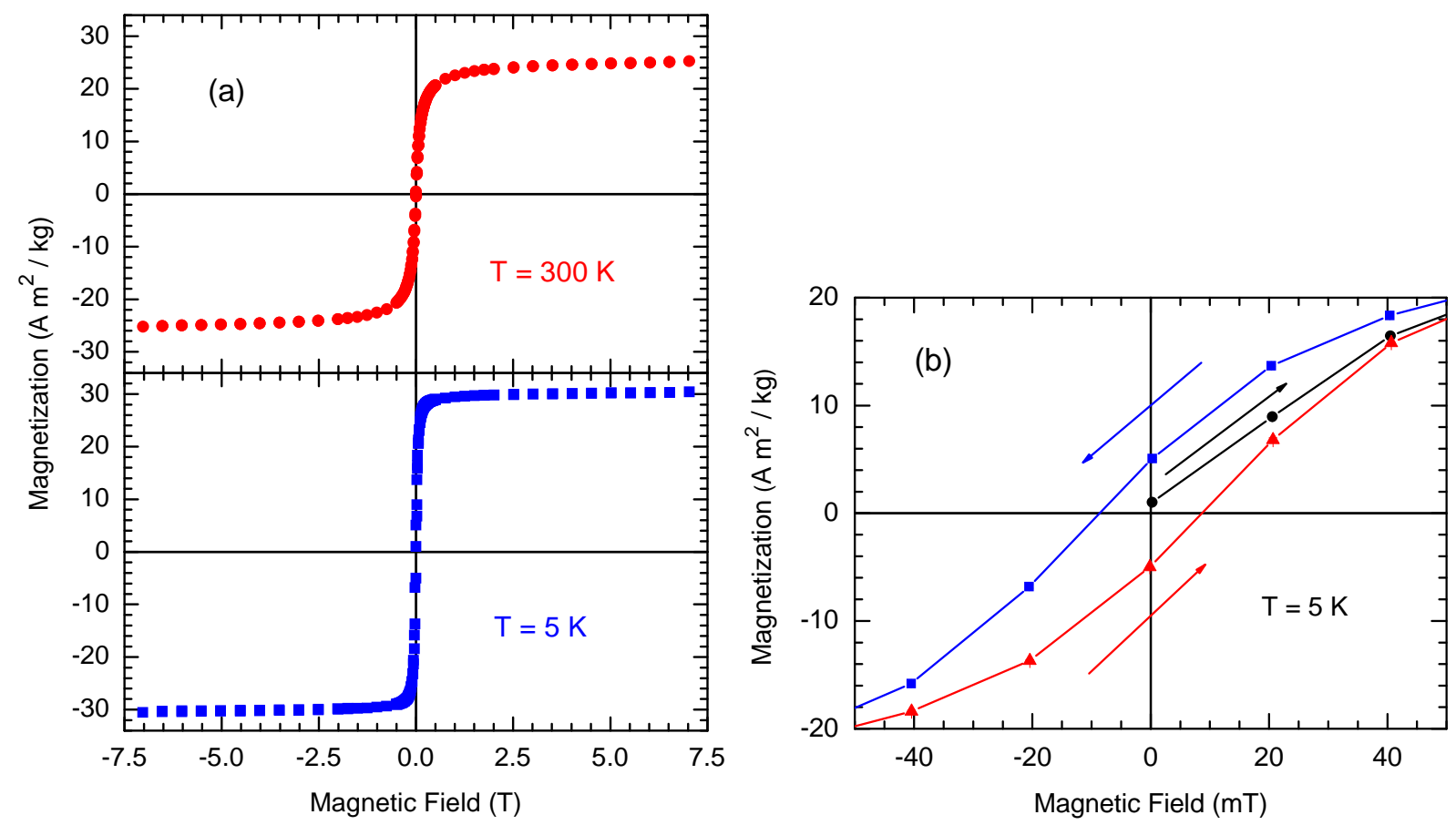

Though the sample is largely saturated by $250 \mathrm{mT}$ (consistent with the presence of magnetite or maghemite; both low coercivity iron oxides), saturation magnetization - the magnetization at which the electron spins are maximally aligned with the applied field- $\left(M_{\mathrm{sat}}\right)$ is not fully achieved at $300 \mathrm{~K}$ in $7 \mathrm{~T}$, indicating the possible presence of high-coercivity impurities or oxidation products such as hematite $\left(\alpha-\mathrm{Fe}_{2} \mathrm{O}_{3}\right)$ and/or goethite $(\mathrm{FeOOH})$. Taking the value at the highest field $(T=300 \mathrm{~K}$, 
$\mathrm{B}=7 \mathrm{~T}) M_{\text {sat }}=25.2 \mathrm{Am}^{2} / \mathrm{kg}$ is just over $1 / 3 M_{\text {sat }}$ for $\mathrm{Fe}_{3} \mathrm{O}_{4}[15,16]$; however, a direct comparison requires attention to composition, size, and surface properties [17]. The difference between $M_{\text {sat }}$ for pure maghemite and/or magnetite ( $c a .80-92 \mathrm{Am}^{2} / \mathrm{kg}$ ) and Feraheme is due to the diamagnetic nature of the polymer matrix within which the iron oxide cores are dispersed. At $300 \mathrm{~K}$, the coercive magnetic field $\left(H_{\mathrm{c}}\right)$ could only be bounded to be less than $2 \mathrm{mT}$. At $5 \mathrm{~K}, H_{\mathrm{c}}=8.5 \pm 1.5 \mathrm{mT}$. The temperature dependence of the magnetization, after field-cooling from $300 \mathrm{~K}$ to $2 \mathrm{~K}$ while in a continuous field of $10 \mathrm{mT}$, is shown in Figure 4 and indicates a mean blocking temperature of ca. $50 \mathrm{~K}$.

Figure 4. Temperature dependence of the magnetization (a) after field cooling (FC) from $300 \mathrm{~K}$ in $10 \mathrm{mT}$ and measuring while warming and (b) after zero-field cooling (ZFC) from $300 \mathrm{~K}$ to $5 \mathrm{~K}$, where a field of $1 \mathrm{mT}$ was applied before measuring while warming.

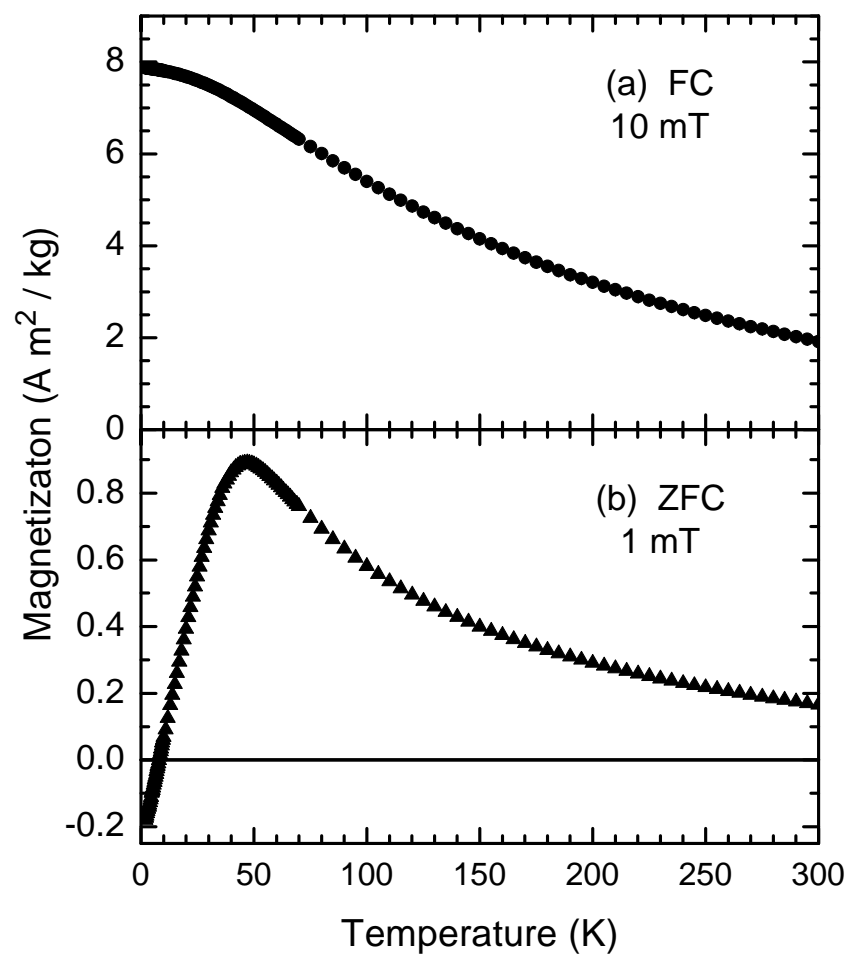

\subsection{Magnetic Fluid Hyperthermia}

Measurement of the heating ability of these particles is important for potential applications in magnetic fluid hyperthermia (MFH) — a technique being investigated for the treatment of solid tumors. MFH relies on the coupling of AC magnetic fields to magnetic nanoparticles (generally iron oxides) dispersed within the tumor. The field applied is of sufficient strength and frequency to induce heating in the particles - primarily via Néel relaxation in superparamagnetic particles [4]. Although the applied field heats the magnetic nanoparticles, the surrounding tissue does not couple to the field in the same way and is left relatively unaffected due to the fact that it is predominantly diamagnetic. This enables the tumor to be specifically targeted even if the field is applied over a relatively large volume of tissue. In practice it has proven difficult to scale up the targeting and distribution of the magnetic nanoparticles within the tumor from small animals to humans. Recent advances in nanoparticle functionalization and cell receptor targeting, however, may provide a way around this drawback $[1,4,18]$. 
In order to make a preliminary evaluation of this potential, we performed an initial heating experiment in water at $340 \mathrm{kHz}$ and $37.5 \mathrm{kA} / \mathrm{m}$. Results indicate that relatively rapid heating of the Feraheme suspension occurs at varying concentrations between $2 \mathrm{mg} / \mathrm{mL}$ and $30 \mathrm{mg} / \mathrm{mL}$. The highest concentration tested $(30 \mathrm{mg} / \mathrm{mL})$ produced a temperature increase of $26^{\circ} \mathrm{C}$ in $120 \mathrm{~s}$, while the lowest concentration produced a temperature increase of $2{ }^{\circ} \mathrm{C}$ over the same time period compared to a water control (Figure 5). These temperature rises equate to a mean Specific Absorption Rates (SAR) of approximately $50.5 \mathrm{~W} / \mathrm{kg}( \pm 17.7 \mathrm{SD})$. At the lowest concentration, this temperature rise is probably not sufficient to induce cell death. However, at concentrations of $10 \mathrm{mg} / \mathrm{mL}$ and higher, the observed temperature rises of more than $10{ }^{\circ} \mathrm{C}$ should be sufficient to induce cell death through both apoptosis and necrosis, which occurs with sustained (>30 min) temperature rises of approximately $5{ }^{\circ} \mathrm{C}$ above body temperature (For review see [4]).

Figure 5. Feraheme suspension temperature rise vs. time at concentrations of $2 \mathrm{mg} / \mathrm{mL}$, $10 \mathrm{mg} / \mathrm{mL}, 15 \mathrm{mg} / \mathrm{mL}$ and $30 \mathrm{mg} / \mathrm{mL}$ in $1 \mathrm{~mL}$ water.

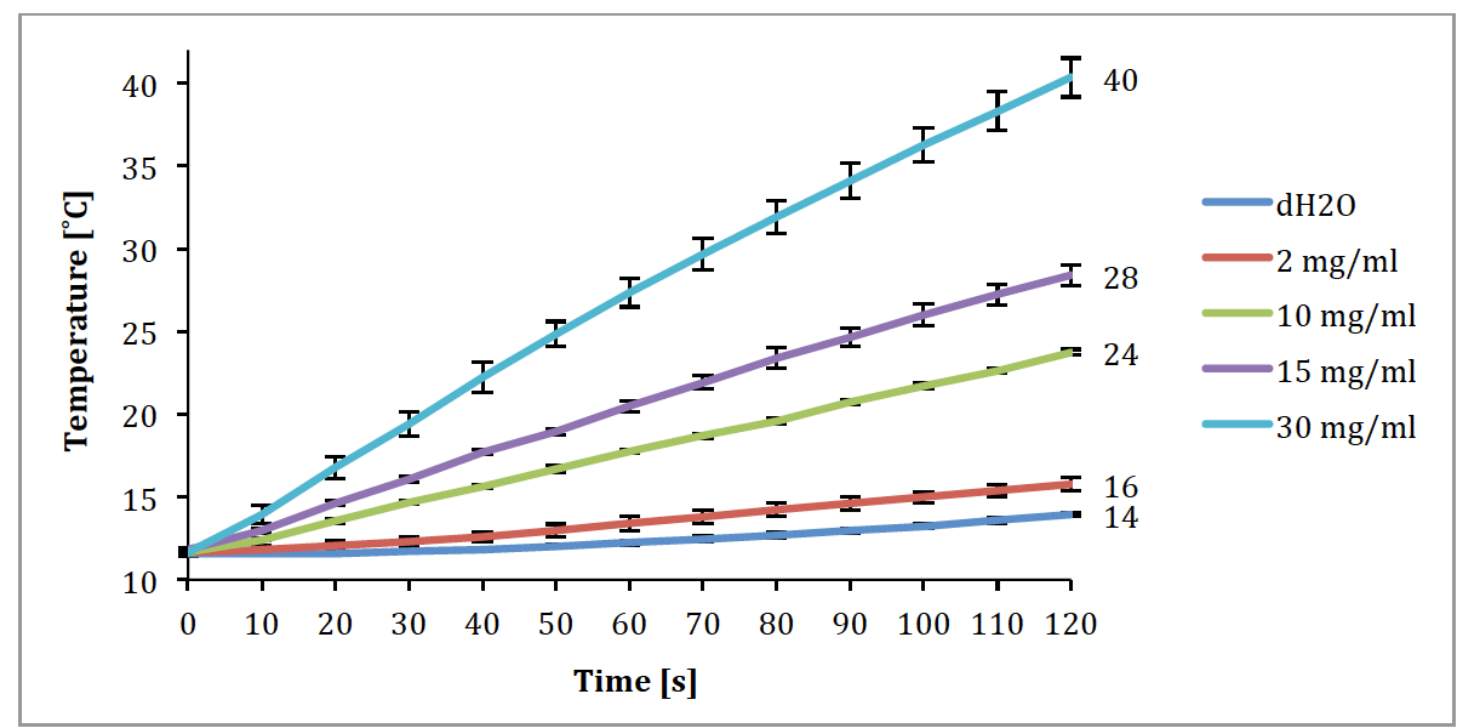

\section{Experimental Section}

\subsection{Feraheme Samples}

Vials of Feraheme $(17 \mathrm{~mL})$ were purchased commercially and consisted of $510 \mathrm{mg}$ of elemental iron per vial (30 mg/mL of iron and $122 \mathrm{mg} / \mathrm{mL}$ of particles). Several different lot numbers were used and showed no significant differences in measurements. They were stored at the recommended temperature of $20{ }^{\circ} \mathrm{C}$ before use, and were used before the expiration date on the vial. Samples for SQUID magnetometry analysis were freeze-dried. The label states that the material containing the iron oxide particles is "polyglucose sorbitol carboxymethylether", but no analysis of the organic part was attempted.

\subsection{High Resolution Transmission Electron Microscopy (HRTEM)}

Microscopy was performed on a JEOL 2010F HRTEM at $200 \mathrm{kV}$. Copper TEM grids were prepared by diluting Feraheme 50 times in double-distilled, deionized water. This solution was then pipetted onto TEM grids, which were placed over filter paper to absorb any excess fluid. The Formvar 
TEM grids were then covered and allowed to dry overnight. Particle size analysis was conducted by measuring the diameter of 232 particles using NIH ImageJ. Energy dispersive X-ray spectroscopy (EDX) analysis (Oxford Instruments EDS X-ray Microanalysis System coupled to the HRTEM microscope) and selected area electron diffraction were performed on one sample of Feraheme prepared as described above.

\subsection{Superconducting Quantum Interference Device (SQUID) Magnetometry}

Analysis of the magnetic properties of Feraheme was conducted using data acquired with a Quantum Design MPMS XL superconducting quantum interference device (SQUID) magnetometer. A sample of Feraheme was freeze-dried and $11.35 \mathrm{mg}$ (dry weight) was packed into gel caps for insertion into the instrument. The background signal from the gel-caps is known to be significantly less than the signal arising from the sample, so the background was not subtracted. Magnetic hysteresis loops (magnetization $[\mathrm{M}]$ vs. applied magnetic field $[\mathrm{H}]$ ) were measured at $5 \mathrm{~K}$ and $300 \mathrm{~K}$ in fields up to $\pm 7 \mathrm{~T}$. The temperature dependence of magnetization was measured after cooling from $300 \mathrm{~K}$ to $5 \mathrm{~K}$ in a $10 \mathrm{mT}$ field and subsequently measured while warming in a $10 \mathrm{mT}$ field. Zero-field-cooled magnetization was measured upon warming from $5 \mathrm{~K}$ in static field of about $1 \mathrm{mT}$ after cooling from $300 \mathrm{~K}$ to $5 \mathrm{~K}$ in zero field.

\subsection{Magnetic Fluid Hyperthermia (MFH)}

The suitability of Feraheme for magnetic fluid hyperthermia (MFH) applications was evaluated using an Ambrell AC coil system running at $340 \mathrm{kHz}$ and $37.5 \mathrm{kA} / \mathrm{m}$. Stock Feraheme suspensions were diluted in distilled water to concentrations of $2,10,15$ and $30 \mathrm{mg} / \mathrm{mL}$ (particles) and $1 \mathrm{~mL}$ of the new suspensions was then sealed in a sealed PVC vial. The temperature of the suspension was monitored and recorded automatically at $10 \mathrm{~s}$. intervals with an Optical probe (Neoptix Reflex with NEOLink Software) inserted into the suspension. Water without Feraheme particles was evaluated at the same intervals as a control. The starting temperature for both the suspension and the water control was $12{ }^{\circ} \mathrm{C}$. These measurements were repeated four times for each concentration and for the water control.

\section{Conclusions}

Magnetic micro- and nanoparticles are being increasingly employed in biomedical research and, in some cases, clinical diagnostic applications. FDA clearance of Feraheme opens up the possibility of using these particles for biomedical applications other than MRI contrast enhancement. The aim of this study was to better understand the morphological and magnetic properties of these particles in order to begin to evaluate the potential for using Feraheme in clinical applications such as magnetic fluid hyperthermia, in vivo cell targeting and actuation, magnetically targeted drug delivery and in vivo cell tracking.

The superparamagnetic nature of the magnetic cores described here as well as the biocompatible nature of the polymer matrix makes Feraheme ideal for in vivo applications where aggregation of blocked magnetic particles has the potential to cause embolism. The size of the particles allows them to escape the body's Reticuloendothelial surveillance system (RES), while the relatively high magnetic 
moment $\left(>25 \mathrm{Am}^{2} / \mathrm{kg}\right.$ ) for a polymer/iron oxide composite, provides an indication that they could be used for intracellular loading in cell targeting applications.

Initial evaluation of the heating ability of Feraheme also indicates that the particles have the potential to be used in magnetic fluid hyperthermia applications. The significant and rapid heating above ambient temperature shown here in the higher concentrations indicate that these particles have the potential to induce cell apoptosis and necrosis if delivered to solid tumors at appropriate concentrations. However, it should be noted that these experiments, like many evaluations of magnetic nanoparticles for hyperthermia applications, were done in water without flow. In the body, blood flow through the tissue provides an effective mechanism for heat transport, likely limiting the clinical effectiveness somewhat or requiring higher MNP concentrations. Another caveat to this analysis is that the starting temperature for these experiments was below body temperature $\left(12{ }^{\circ} \mathrm{C}\right)$. Starting at body temperature would likely result in a slower temperature rise and may not result in the full temperature increase observed over duration of this experiment.

The data provided in this study provide a sound foundation for further evaluation of the potential of Feraheme in biomedical and clinical applications beyond their current use in as MRI contrast agents. The field of Mesoscale Magnetic Biomaterials - magnetic biomaterials that range is size from nanometers to microns - is growing rapidly, with applications spanning from those already in use in the clinic and pathology laboratories, such as MRI contrast and cell separation, to more advanced and futuristic applications in cancer treatment, tissue engineering and regenerative medicine. For all of these in vivo applications, the development and use of biocompatible magnetic nanoparticles will be a pre-requisite. In addition, re-purposing formulations that are already in use may provide a shorter route to the clinic for many of these applications. The work presented here represents an initial step in investigating this idea by rigorously characterizing Feraheme and conducting a preliminary investigation for one of these potential future applications - magnetic fluid hyperthermia.

\section{Acknowledgments}

This work was supported, in part, by the National Science Foundation (NSF) through support of the National High Magnetic Field Laboratory (NHMFL) via cooperative agreement DMR-0654118 and by the NIH/NCRR Clinical and Translational Science Award to the University of Florida UL1 RR029890. The authors thank Mark Meisel and Matthieu F. Dumont, Department of Physics, University of Florida, for the SQUID measurements.

\section{Conflicts of Interest}

The authors declare no conflict of interest.

\section{References}

1. Pankhurst, Q.A.; Thanh, N.K.T.; Jones, S.K.; Dobson, J. Progress in applications of magnetic nanoparticles in biomedicine. J. Phys. D 2009, 42, 224001:1-224001:15.

2. Liu, F.J.; Laurent, S.; Fattahi, H.; Elst, L.V.; Muller, R.N. Superparamagnetic nanosystems based on iron oxide nanoparticles for biomedical imaging. Nanomedicine 2011, 6, 19-528. 
3. Stephen, Z.R.; Kievit, F.M.; Zhang, M.Q. Magnetite nanoparticles for medical MR imaging. Mat. Today 2011, 14, 330-338.

4. Pankhurst, Q.A.; Connoly, J.; Jones, S.K.; Dobson, J. Applications of magnetic nanoparticles in biomedicine. J. Phys. D 2003, 36, R167-R181.

5. Neuwelt, E.A.; Varallyay, P.; Bago, A.G.; Muldoon, L.L.; Nesbit, G.; Nixon, R. Imaging of iron oxide nanoparticles by MR and light microscopy in patients with malignant brain tumours. Neuropath. Appl. Neurobiol. 2004, 30, 456-471.

6. Kumar, M.; Medarova, Z.; Pantazopoulos, P.; Dai, G.P.; Moore, A. Novel membrane-permeable contrast agent for brain tumor detection by MRI. Magn. Res. Med. 2010, 63, 617-624.

7. Berman, S.M.C.; Walczak, P.; Bulte, J.W.M. Tracking stem cells using magnetic nanoparticles. Wiley Interdiscip. Rev. Nanomed. Nanobiotech. 2011, 3, 343-355.

8. Herynek, V.; Berkova, Z.; Horak, D.; Babic, M.; Jirak, D.; Saudek, F.; Hajek, M. Alternative labels for visualization of pancreatic islets. Proc. Intl. Soc. Mag. Reson. Med. 2010, 18, 4200.

9. Provenzano, R.; Schiller, B.; Rao, M.; Coyne, D.; Brenner, L.; Pereira, B.J. Ferumoxytol as an intravenous iron replacement therapy in hemodialysis patients. CJASN 2009, 4, 386-393.

10. Chen, S. Polymer-Coated Iron Oxide Nanoparticles for Medical Imaging. Ph.D. Thesis, Massachusetts Institute of Technology, Cambridge, UK, 2010; p. 158.

11. Balakrishnan, V.S.; Rao, M.; Kasuz, A.T.; Brenner, L.; Pereira, B.J.; Frigo, T.B.; Lewis, J.M. Physicochemical properties of ferumoxytol, a new intravenous iron preparation Eur. J. Clin. Invest. 2009, 39, 489-496.

12. Barick, K.C.; Aslam, M.; Lin, Y.P.; Bahdur, D.; Prasad, P.V.; Dravid, V.P. Novel and efficient MRactiveaqueous colloidal $\mathrm{Fe}_{3} \mathrm{O}_{4}$ nanoparticle assemblies. J. Mater. Chem. 2009, 19, 7023-7029.

13. Dobson, J. Remote control of cellular behavior with magnetic nanoparticles. Nat. Nanotechnol. 2008, 3, 139-143.

14. Ku, S.K.; Lin, J.; Dravid, V.P.; Joshi, H.M. Biological applications of size-controlled iron oxide magnetic nanostructures. Nanoscape 2010, 7, 38-43.

15. Ge, Q.; Su, J.; Chung, T.-S.; Amy, G. Hydrophilic superparamagnetic nanoparticles: Synthesis, characterization and performance in forward osmosis process. Ind. Eng. Chem. Res. 2011, 50, 382-388.

16. Stjerndahl, M.; Andersson, M.; Hall, H.E.; Pajerowski, D.M.; Meisel, M.W.; Duran, R.S. Superparamagnetic $\mathrm{Fe}_{3} \mathrm{O}_{4} / \mathrm{SiO}_{2}$ nanocomposites: Enabling the tuning of both the iron oxide load and the size of the nanoparticles. Langmuir 2008, 24, 3532-3536.

17. Demortiere, A.; Panissod, P.; Pichon, B.P.; Pourroy, G.; Guillon, D.; Donnio, B.; Begin-Colin, S. Size-dependent properties of magnetic iron oxide nanocrystals. Nanoscale 2011, 3, 225-232.

18. Creixell, M.; Bohorquez, A.C.; Torres-Lugo, M.; Rinaldi, C. EGFR-targeted magnetic nanoparticle heaters can kill cancer cells without a perceptible temperature rise. ACS Nano 2011, 5, 7124-7129.

(C) 2013 by the authors; licensee MDPI, Basel, Switzerland. This article is an open access article distributed under the terms and conditions of the Creative Commons Attribution license (http://creativecommons.org/licenses/by/3.0/). 